\title{
Recent patent applications in proteomics
}

\begin{tabular}{|c|c|c|c|c|c|}
\hline Patent \# & Subject & Assignee(s) & Inventor(s) & $\begin{array}{l}\text { Priority } \\
\text { application } \\
\text { date }\end{array}$ & $\begin{array}{l}\text { Publication } \\
\text { date }\end{array}$ \\
\hline WO 2006095158 & $\begin{array}{l}\text { A method for assigning a treatment and/or monitoring } \\
\text { regime to a cancer patient, involving determining the } \\
\text { Raf kinase inhibitor protein (PKIP) expression level } \\
\text { in a sample from a primary tumor obtained from the } \\
\text { patient. }\end{array}$ & $\begin{array}{l}\text { Al-Mulla F, } \\
\text { Hagan S, } \\
\text { Kolch W }\end{array}$ & $\begin{array}{l}\text { Al-Mulla F, } \\
\text { Hagan S, } \\
\text { Kolch W }\end{array}$ & 3/7/2005 & $9 / 14 / 2006$ \\
\hline JP 2006230251 & $\begin{array}{l}\text { A fusion protein expression vector, comprising a } \\
\text { restriction enzyme site for inserting the gene } \\
\text { encoding a protein derived from Halobacterium } \\
\text { and a gene encoding a target protein downstream } \\
\text { of the Halobacterium gene, and a protease cleav- } \\
\text { age site, where the target protein is expressed as a } \\
\text { fusion protein along with the protein derived from } \\
\text { Halobacterium. }\end{array}$ & $\begin{array}{l}\text { Kagoshima University } \\
\text { (Kagoshima, Japan) }\end{array}$ & $\begin{array}{l}\text { Ishibashi M, } \\
\text { Tokunaga H, } \\
\text { Tokunaga M }\end{array}$ & $2 / 23 / 2005$ & 9/7/2006 \\
\hline EP 1698702 & $\begin{array}{l}\text { A polynucleotide comprising a functionally linked } \\
\text { nucleic acid sequence comprising an autonomously } \\
\text { replicating sequence element, a nucleic acid sequence } \\
\text { comprising a ribosomal DNA (rDNA) gene, a nucleic } \\
\text { acid sequence encoding a selection marker and a } \\
\text { nucleic acid sequence comprising an expressible } \\
\text { nucleic acid sequence encoding a polypeptide and a } \\
\text { promoter nucleic acid sequence governing the expres- } \\
\text { sion of the expressible sequence; useful for manufac- } \\
\text { turing a pharmaceutical composition. }\end{array}$ & Gellissen G & Gellissen G & $3 / 2 / 2005$ & 9/6/2006 \\
\hline $\begin{array}{l}\text { US } 20060194284 \text {, } \\
\text { WO } 2006089613\end{array}$ & $\begin{array}{l}\text { A host organism containing vitamin K reductase com- } \\
\text { plex subunit } 1 \text { (VKORC1) and vitamin K-dependent } \\
\text { (VKD) protein; useful in studying the improvement of } \\
\text { the productivity of recombinant VKD protein expression. }\end{array}$ & $\begin{array}{l}\text { Baxter Healthcare, } \\
\text { Baxter International } \\
\text { (Deerfield, IL, USA) }\end{array}$ & $\begin{array}{l}\text { Boehm E, } \\
\text { Scheiflinger } F\end{array}$ & $2 / 28 / 2005$ & $\begin{array}{l}8 / 31 / 2006 \\
8 / 31 / 2006\end{array}$ \\
\hline WO 2006091483 & $\begin{array}{l}\text { A phage-derived vector comprising one or more } \\
\text { factors that direct expression of a polypeptide of } \\
\text { interest and at least one conditional promoter } \\
\text { operably linked to coding sequences expressing } \\
\text { one or more late phage transcripts; useful for cloning } \\
\text { or expressing a heterologous polypeptide of interest. }\end{array}$ & Tabaczynski D & Tabaczynski D & $2 / 22 / 2005$ & $8 / 31 / 2006$ \\
\hline WO 2006077126 & $\begin{array}{l}\text { A method of diagnosing multiple sclerosis in vitro in a } \\
\text { patient, comprising providing a biological sample from } \\
\text { the patient and a biological sample from a healthy } \\
\text { donor, and determining the level of expression of } \\
\text { CX3CR1 gene or protein expression in the samples. }\end{array}$ & Schering (Berlin) & $\begin{array}{l}\text { Infante-Duarte C, } \\
\text { Stuerzebecher C, } \\
\text { Zipp-Nitsch F }\end{array}$ & $1 / 19 / 2005$ & $7 / 27 / 2006$ \\
\hline WO 2006073976 & $\begin{array}{l}\text { Nucleic acid composition useful for enhancing expres- } \\
\text { sion levels or solubility of protein of interest, compris- } \\
\text { ing nucleic acids encoding a small ubiquitin-related } \\
\text { modifier (SUMO) protein, protein of interest and } \\
\text { purification tags }\end{array}$ & $\begin{array}{l}\text { LifeSensors } \\
\text { (Malvern, PA, USA) }\end{array}$ & $\begin{array}{l}\text { Butt T, Sterner D, } \\
\text { Zuo X }\end{array}$ & $12 / 30 / 2004$ & $7 / 13 / 2006$ \\
\hline WO 2006073320 & $\begin{array}{l}\text { A UBP1 protease mutant containing certain amino } \\
\text { acid substitutions and deletions; useful for obtaining } \\
\text { ubiquitin-cleaving enzymatic activity, or for synthesiz- } \\
\text { ing recombinant proteins expressing g ubiquitin. }\end{array}$ & $\begin{array}{l}\text { Instytut Biotechnologii } \\
\text { i Antybiotyków (Warsaw) }\end{array}$ & $\begin{array}{l}\text { Chojnacka L, } \\
\text { Mazurkiewicz A, } \\
\text { Plucienniczak A, } \\
\text { Wojtowicz A }\end{array}$ & $1 / 10 / 2005$ & $7 / 13 / 2006$ \\
\hline $\begin{array}{l}\text { WO 2006069203, } \\
\text { US } 20060216760\end{array}$ & $\begin{array}{l}\text { A method of determining protein expression patterns in } \\
\text { a cell or a tissue comprising contacting the cell or the } \\
\text { tissue with a nonnatural amino acid comprising a first } \\
\text { reactive group. }\end{array}$ & $\begin{array}{l}\text { California Institute of } \\
\text { Technology } \\
\text { (Pasadena, CA, USA) }\end{array}$ & $\begin{array}{l}\text { Dieterich DC, } \\
\text { Link AJ, } \\
\text { Schuman E, } \\
\text { Tirrell DA }\end{array}$ & $12 / 22 / 2004$ & $\begin{array}{l}\text { 6/29/2006, } \\
6 / 28 / 2006\end{array}$ \\
\hline CN 1737150 & $\begin{array}{l}\text { An adiponectin-glucagon-like peptide-1-like peptide } \\
\text { recombinant protein expression vector and construction. }\end{array}$ & $\begin{array}{l}\text { Zhejiang University } \\
\text { (Zhejiang, China) }\end{array}$ & $\begin{array}{l}\text { Gu W, Zhan Y, } \\
\text { Zhao J, Zhao T }\end{array}$ & $7 / 22 / 2005$ & $2 / 22 / 2006$ \\
\hline
\end{tabular}

Source: Thomson Scientific Search Service. The status of each application is slightly different from country to country. For further details, contact Thomson Scientific, 1800 Diagonal Road, Suite 250, Alexandria, Virginia 22314, USA. Tel: 1 (800) 337-9368 (http://www.thomson.com/scientific). 